Int. J. Dev. Biol. 59: 487-496 (2015)

doi: $10.1387 / \mathrm{ijdb} .150363 \mathrm{cx}$

\title{
iTRAQ-based proteomic analysis of adaptive response in the regenerating limb of the Cynops orientalis newt
}

\author{
XIAO-FANG GENG ${ }^{1,2,3}$, JIAN-LIN GUO 2,3,4, XIA-YAN ZANG ${ }^{2,3,4}$, JING-YAN SUN ${ }^{2,3,4}$, PENG-FEI LI 2,3,4, \\ FU-CHUN ZHANG ${ }^{1 *}$ and CUN-SHUAN XU2,3,4* \\ ${ }^{1}$ Xinjiang Key Laboratory of Biological Resources and Genetic Engineering, College of Life Science and Technology, \\ Xinjiang University, Urumqi, ${ }^{2}$ State Key Laboratory Cultivation Base for Cell Differentiation Regulation, Henan \\ Normal University, Xinxiang, ${ }^{3}$ Henan Engineering Laboratory for Bioengineering and Drug Development, Henan \\ Normal University, Xinxiang and ${ }^{4}$ College of Life Science, Henan Normal University, Xinxiang, China
}

\begin{abstract}
The newt has the powerful capacity to regenerate lost limbs following amputation, and represents an excellent model organism to study regenerative processes. However, the molecular basis of the adaptive response in the regenerating limb of the Chinese fire-bellied newt Cynops orientalis immediately after amputation remains unclear. To better understand the adaptive response immediately after limb amputation at the protein level, we used isobaric tags for relative and absolute quantitation (iTRAQ) coupled with LC-MS/MS methods to analyze changes in the proteome of the regenerating newt limb that occurred $2 \mathrm{~h}$ and $8 \mathrm{~h}$ after amputation. We identified 152 proteins with more than 1.5 -fold change in expression compared to control. GO annotation analysis classified these proteins into several categories such as signaling, $\mathrm{Ca}^{2+}$ binding and translocation, transcription and translation, immune response, cell death, cytoskeleton, metabolism, etc. Further ingenuity pathway analysis (IPA) showed that several signaling pathways were significantly changed at $\mathbf{2} \mathrm{h}$ and $\mathbf{8} \mathrm{h}$ after amputation, including EIF2 signaling, acute phase response signaling, tight junction signaling and calcium signaling, suggesting these pathways may be closely related to the adaptive response immediately after limb amputation. This work provides novel insights into understanding the molecular processes related to newt limb regeneration immediately after amputation, and a basis for further study of regenerative medicine.
\end{abstract}

KEY WORDS: Cynops orientalis, limb regeneration, proteomic, stress response, cell death

Among vertebrates, urodele salamanders possess remarkable capability to regenerate appendages from any level of amputation through blastema formation. Subsequently, blastema cells that morphologically resemble mesenchymal stem-like cells self-organize into the amputated limb parts (Bryant et al., 2002, Nye et al., 2003). Adult newt has already been used as an important model for the limb regeneration studies. The process of limb regeneration can be divided into three major phases: wound healing and dedifferentiation; blastema accumulation and blastema growth; differentiation and morphogenesis (Iten and Bryant, 1973). Following amputation, the wound surface is covered rapidly by epithelial cells, which form the wound epidermis at the end of the stump. More importantly, a specialized epithelium provides signals to the underlying cells of the stump to dedifferentiate and/or maintain cell proliferation (Kumar et al., 2007). After that, an avascular accumulation blastema was formed mainly by the dedifferentiation of the liberated cells at the amputated site through proteolysis of extracellular matrix (Brockes and Kumar, 2002, Morrison et al., 2006). Once formed, the accumulation blastema undergoes proliferation, differentiation and morphogenesis to regenerate the limb (Vascotto et al., 2005).

Analysis of the molecular basis of urodele limb regeneration is useful for understanding how we might achieve its ultimate goal of

Abbreviations used in this paper: iTRAQ, isobaric tags for relative and absolute quantitation; IPA, ingenuity pathway analysis.

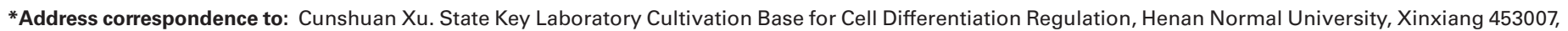
China. Tel.: +860373-3326001; Fax: +860373-3325410. E-mail: cellkeylab@126.com
} 
stimulating limb regeneration of humans. More global analyses have recently been conducted using microarrays and high-throughput sequencing to compare transcriptional profiles of regenerating versus intact limb tissues, or to compare blastemas of regenerationcompetent versus regeneration-deficient limbs (Grow et al., 2006, Monaghan et al., 2009, Wu et al., 2013).

Recently, a number of studies have been carried out on protein separation and identification in regenerating urodele limb using gel-based proteomic method (Geng et al., 2014, Tsonis, 1993, Tsonis et al., 1992). Besides, Rao et al., (Rao et al., 2009) utilized a label-free LC-MS/MS quantitative approach to analyze blastema formation in regenerating axolotl hind limbs after amputation, and reported that the amputated urodele limb used a combination of mechanisms to regulate apoptosis during blastema formation that might be essential for dedifferentiation. Following amputation, there is a wide range of signals that induce proteolysis of extracellular matrix and promote liberation of cells from their initial tissue organization. To contradict this stress, cells use a variety of mechanisms to prevent apoptosis, including the up-regulation of anti-apoptotic pathways, metabolism reduction, and the initiation of unfolded protein response (Rao et al., 2009). Although molecular details about the process of limb regeneration in amphibian have been uncovered, a specific event that takes place in regenerating newt limb immediately after amputation needs to be further studied.

In the present study, an isobaric tag for relative and absolute quantitation (iTRAQ) labeling combined with LC-MS/MS was utilized to determine the proteome changes of the regenerating newt limb immediately after amputation. The results revealed that 152 proteins showed more than 1.5-fold change in expression at $2 \mathrm{~h}$ and $8 \mathrm{~h}$ after amputation compared to control. Functional annotation found that these proteins were mainly involved in several functional categories including signaling, $\mathrm{Ca}^{2+}$ binding and translocation, apoptosis and metabolism. Further IPA analysis showed that several signaling pathways including acute phase response signaling and calcium signaling maybe closely related to the adaptive response immediately after limb amputation. This work provides novel insights into understanding the molecular process related to newt limb regeneration.

\section{Results}

\section{Proteome alterations in the regenerating newt limbs immediately after amputation}

To identify proteins associated with the adaptive response in the regenerating newt limbs immediately after amputation, iTRAQ was employed to assess proteome changes at $2 \mathrm{~h}$ and $8 \mathrm{~h}$ following amputation, and $\mathrm{Q}$-Exactive mass spectrometer was used to obtain better coverage of tissue proteome. The mass data was searched against the SwissProt database using Mascot 2.2 search engine. The peptide FDR $\leq 0.01$ and each protein with at least 2 unique peptides were utilized to filter out the data, and 1787 proteins were identified (Supplementary table 1). The protein mass distribution mainly concentrated in 10-100 kDa which made up $87.01 \%$ of the proteins. The proteins with $2-5$ peptides, $6-10$ peptides, and above 11 peptides comprised 1067, 410 and 310, respectively (Fig.1A). Protein sequence coverage with below 10\%, 10-20\%, $20-30 \%, 30-40 \%, 40-50 \%$, and $50-100 \%$ variation accounted for $22.38 \%, 25.24 \%, 18.69 \%, 14.05 \%, 10.24 \%$ and $9.40 \%$ coverage, respectively (Fig.1B).

Proteins that showed greater than 1.5-fold change in relative abundance were defined as significantly changed proteins. In total, 152 proteins were found to be differentially expressed at $2 \mathrm{~h}$ and $8 \mathrm{~h}$ after amputation as compared to control group, of which 91 proteins were up-regulated and 61 proteins down-regulated. Later on, to understand the expression trend as a whole, clustering was used in this study. Ratio values of 152 significantly changed proteins were log (base 2) transformed, and then hierarchical clustering was performed using Cluster 3.0 and TreeView software. A global intensity map of the differentially expressed proteins is shown in Fig.2.

\section{Functional categories of the significantly changed proteins} in the regenerating newt limbs immediately after amputation

Fig. 3 stratifies the proteins according to biological process and molecular function. Among the 152 differentially expressed proteins, 129 proteins were categorized into seven groups according to their functional properties: (i) signaling; (ii) $\mathrm{Ca}^{2+}$ binding and
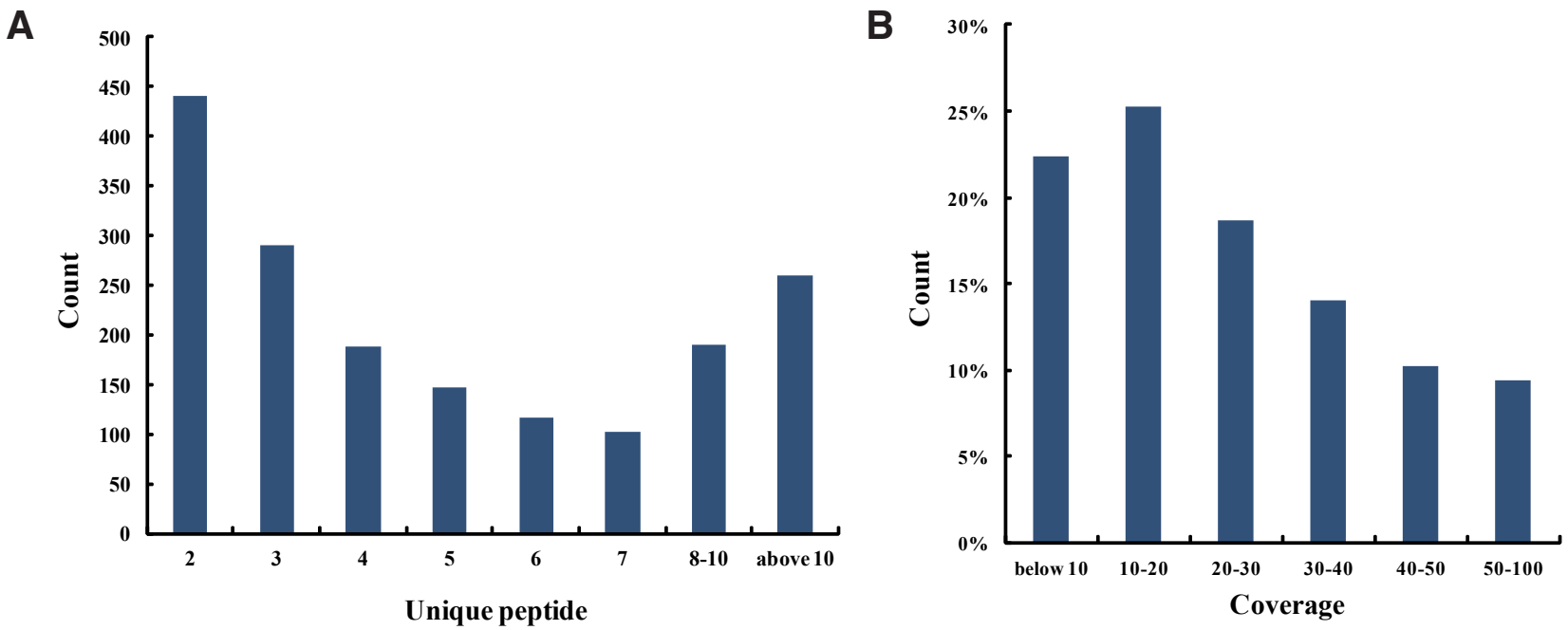

Fig. 1. The unique peptides and the sequence coverage of the identified proteins. (A) The number of the identified proteins with different unique peptides. (B) The percent of the identified proteins with different sequence coverage. 
translocation; (iii) transcription and translation; (iv) cytoskeleton; (v) immune response and cell death; (vi) carbohydrate, lipid, and energy metabolism; and (vii) amino acid and purine metabolism (Table 1). Below, we describe the results for each of the biological categories in order.

8 differentially expressed proteins belong to proteins associated with signaling. Among them, RAN GTPase activating protein 1, SPARC-like protein 1, RAC-beta serine/threonine-protein kinase and cytoplasmic FMR1-interacting protein 1 were up-regulated immediately after amputation.

14 differentially expressed proteins belong to proteins associated with $\mathrm{Ca}^{2+}$ binding and translocation, and the number of up-regulated proteins was significantly more than that of down-regulated proteins. These proteins included solute carrier family 25 members, $\mathbf{S} 100$ calcium binding protein $\mathrm{A} 10$, sarcoendoplasmic reticulum calcium ATPase, tricarboxylate transport protein, etc.

21 differentially expressed proteins were involved in transcription and translation. We found that most of the proteins related to translation were significantly downregulated, especially at $2 \mathrm{~h}$, including ribosomal proteins, eukaryotic translation initiation factors and elongation factors.

15 differentially expressed proteins belong to proteins associated with cytoskeleton and extracellular matrix. Among them, seven proteins were up-regulated at $2 \mathrm{~h}$ and $8 \mathrm{~h}$ after amputation, including myosins, tubulins, and regulator of microtubule dynamics protein 1.

18 differentially expressed proteins were involved in immune response and cell death. We found that the number of up-regulated proteins was significantly more than that of down-regulated proteins. There proteins including complement component $\mathrm{C} 3$, stress-70 protein, heat shock protein 5, superoxide dismutase [Cu-Zn], etc.

53 differentially expressed proteins were found to participate in metabolism. Among them, 36 proteins were involved in carbohydrate, lipid, and energy metabolism. Interestingly, the number of the up-regulated proteins was 2 -fold lower than that of the down-regulated proteins at $2 \mathrm{~h}$, and the number of the up-regulated proteins was 2-fold higher than that of the down-regulated proteins at $8 \mathrm{~h}$. More importantly, most of the proteins showed significantly up-regulated at $8 \mathrm{~h}$ after amputation, including proteins related to glycolysis (i.e. phosphoglycerate kinase, glycerol-3-phosphate dehydrogenase 1), tricarboxylic acid cycle (i.e. 2-oxoglutarate dehydrogenase, pyruvate dehydrogenase $\mathrm{E} 1$ component, isocitrate dehydrogenase), electron transport chain (i.e. NADH dehydrogenase [ubiquinone] iron-sulfur protein 2), and fatty acid oxidation (i.e. acyl-Coenzyme A dehydrogenase, very long-chain specific acyl-CoAdehydrogenase, hydroxyacyl-Coenzyme A dehydrogenase). 17 proteins were involved in amino acid and purine metabolism. Similar to the expression pattern of carbohydrate, lipid, and energy metabolism, most of the proteins showed significantly up-regulated at $8 \mathrm{~h}$ after amputation, including proteins associated with amino acid metabolism (i.e. aspartate aminotransferase, 4-aminobutyrate aminotransferase, alanine aminotransferase) and purine metabolism (i.e. purine nucleoside phosphorylase, nucleoside diphosphate kinase).

\section{Modulation of various signaling pathways at the very early phase of newt limb regeneration}

To further clarify which signaling pathways play important roles at the very early phase of newt limb regeneration, IPA analysis was carried out to connect the differentially expressed proteins with canonical pathways. The significance of a canonical pathway was calculated by a Benjamini-Hochberg corrected Fischer's exact test. The pathway analysis results showed that several signaling

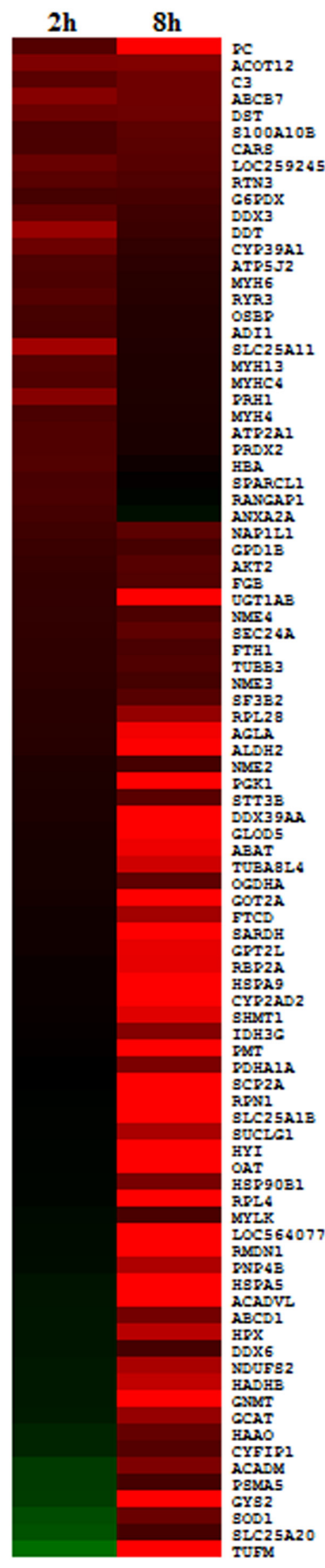

Fig. 2. Global Expression intensity map. HeatMap showing up-regulation (red) and downregulation (green) of proteins identified as 1.5-fold change compared to control. Numbers at each column indicate hours after amputation. Left column: proteins up-regulated at $2 \mathrm{~h}$ and $8 \mathrm{~h}$. Right column: proteins down-regulated at $2 \mathrm{~h}$ and $8 \mathrm{~h}$. 
TABLE 1

PROTEOME ALTERATIONS IN THE REGENERATING NEWT LIMB IMMEDIATELY AFTER AMPUTATION

\begin{tabular}{|c|c|c|c|c|c|c|c|}
\hline Protein name & Genes & MW [kDa] & pl & Coverage & $\begin{array}{c}\text { Unique } \\
\text { Peptides }\end{array}$ & $2 \mathrm{~h} / 0 \mathrm{~h}$ & $8 \mathrm{~h} / 0 \mathrm{~h}$ \\
\hline \multicolumn{8}{|l|}{ Signaling } \\
\hline RAN GTPase activating protein 1 & RANGAP1 & 46.4 & 4.6 & 4.2 & 2 & 1.57 & 0.97 \\
\hline SPARC-like protein 1 & SPARCL1 & 29.7 & 5.0 & 14.2 & 2 & 1.56 & 1.03 \\
\hline Annexin A2 & ANXA2 & 38.1 & 7.7 & 19.6 & 5 & 1.51 & 0.91 \\
\hline Cytoplasmic FMR1-interacting protein 1 & CYFIP1 & 144.8 & 6.9 & 2.6 & 3 & 0.80 & 1.68 \\
\hline B-cell receptor-associated protein 31 & BCAP31 & 28.0 & 8.6 & 8.5 & 2 & 0.66 & 0.69 \\
\hline ERO1-like protein alpha & ERO1L & 53.9 & 5.9 & 5.2 & 2 & 0.64 & 0.51 \\
\hline Inositol monophosphatase 1 & IMPA1 & 30.5 & 5.3 & 15.9 & 3 & 0.60 & 0.66 \\
\hline RAB10, member RAS oncogene family & RAB10 & 22.5 & 8.4 & 22.5 & 2 & 0.64 & 0.68 \\
\hline \multicolumn{8}{|l|}{$\mathrm{Ca}^{2+}$ binding and translocation } \\
\hline ATP-binding cassette sub-family B member 7 & ABCB7 & 73.7 & 9.1 & 3.3 & 2 & 2.26 & 1.96 \\
\hline S100 calcium binding protein A10 & S100A10 & 11.1 & 5.5 & 24.0 & 2 & 1.57 & 1.76 \\
\hline Dystonin & DST & 607.8 & 5.8 & 0.4 & 2 & 1.91 & 1.94 \\
\hline Ryanodine receptor 3 & RYR3 & 548.4 & 6.0 & 0.5 & 2 & 1.67 & 1.26 \\
\hline Sarcoendoplasmic reticulum calcium ATPase & ATP2A1 & 108.7 & 5.2 & 20.5 & 6 & 1.63 & 1.18 \\
\hline Oxysterol-binding protein & OSBP & 84.9 & 7.3 & 3.6 & 3 & 1.52 & 1.24 \\
\hline Hemoglobin subunit alpha & HBA & 15.7 & 7.7 & 21.8 & 2 & 1.66 & 1.10 \\
\hline Solute carrier family 25 member 11 & SLC25A11 & 33.8 & 9.8 & 15.3 & 2 & 2.67 & 1.22 \\
\hline Solute carrier family 22 member 6 & SLC22A6 & 48.6 & 7.0 & 26.6 & 7 & 0.97 & 13.56 \\
\hline Tricarboxylate transport protein, mitochondrial & SLC25A1 & 45.1 & 9.8 & 21.7 & 5 & 0.98 & 9.66 \\
\hline Solute carrier family 25 member 20 & SLC25A20 & 32.8 & 9.5 & 13.3 & 2 & 0.61 & 1.54 \\
\hline Ceruloplasmin & $\mathrm{CP}$ & 124.3 & 6.9 & 6.9 & 6 & 0.32 & 0.34 \\
\hline T-complex protein 1 subunit delta & CCT4 & 58.1 & 8.0 & 22.8 & 5 & 0.66 & 0.93 \\
\hline Transmembrane emp24 domain-containing protein 5 & TMED5 & 26.1 & 4.8 & 14.4 & 3 & 1.06 & 0.59 \\
\hline \multicolumn{8}{|l|}{ Transcription and translation } \\
\hline Cysteine--tRNA ligase, cytoplasmic & CARS & 74.6 & 6.4 & 6.1 & 3 & 1.58 & 1.71 \\
\hline DEAD (Asp-Glu-Ala-Asp) box polypeptide 3 & DDX3X & 78.3 & 8.3 & 13.0 & 2 & 1.78 & 1.46 \\
\hline ATP-dependent RNA helicase DDX39A & DDX39A & 48.9 & 5.6 & 26.9 & 3 & 1.19 & 6.63 \\
\hline Ribosomal protein L4 & RPL4 & 42.5 & 11.1 & 27.2 & 9 & 0.97 & 6.36 \\
\hline Ribophorin-1 & RPN1 & 67.6 & 6.7 & 22.7 & 10 & 0.99 & 5.12 \\
\hline $60 S$ ribosomal protein L28 & RPL28 & 15.6 & 12.1 & 20.3 & 3 & 1.28 & 2.45 \\
\hline Splicing factor $3 \mathrm{~B}$ subunit 2 & SF3B2 & 98.3 & 5.5 & 2.2 & 2 & 1.28 & 1.68 \\
\hline Probable ATP-dependent RNA helicase ddx6 & DDX6 & 54.2 & 8.7 & 12.0 & 4 & 0.88 & 1.54 \\
\hline Nucleosome assembly protein 1 , like 1 & NAP1L1 & 44.4 & 4.5 & 17.4 & 2 & 1.47 & 1.76 \\
\hline $40 S$ ribosomal protein $\$ 9$ & RPS9 & 22.6 & 10.7 & 40.2 & 4 & 0.60 & 0.61 \\
\hline Ribosomal protein S2 & RPS2 & 27.2 & 9.6 & 35.2 & 3 & 0.96 & 0.64 \\
\hline Ribosomal protein S16 & RPS16 & 16.3 & 10.1 & 39.7 & 2 & 0.73 & 0.61 \\
\hline Elongation factor $\mathrm{Tu}$ & TUFM & 49.2 & 6.9 & 17.2 & 5 & 0.52 & 6.44 \\
\hline $60 S$ ribosomal protein $L 7$ & RPL7 & 30.3 & 10.9 & 31.9 & 7 & 0.66 & 0.83 \\
\hline Eukaryotic translation initiation factor $4 \mathrm{~B}$ & EIF4B & 69.0 & 5.8 & 9.5 & 5 & 0.66 & 0.91 \\
\hline $40 S$ ribosomal protein SA & RPSA & 32.8 & 4.9 & 35.6 & 2 & 0.66 & 0.69 \\
\hline Elongation factor 1 -alpha & EEF1A1 & 50.0 & 8.9 & 49.8 & 5 & 0.65 & 0.69 \\
\hline ER membrane protein complex subunit 1 & EMC1 & 111.1 & 7.3 & 4.9 & 5 & 0.64 & 0.71 \\
\hline Eukaryotic translation initiation factor 3 subunit $C$ & EIF3C & 105.4 & 5.8 & 6.3 & 2 & 0.64 & 0.88 \\
\hline Eukaryotic initiation factor 4A-III & EIF4A3 & 46.4 & 6.7 & 12.8 & 2 & 0.63 & 0.69 \\
\hline Far upstream element-binding protein 2 & KHSRP & 74.2 & 6.9 & 10.1 & 5 & 0.62 & 0.88 \\
\hline \multicolumn{8}{|l|}{ Cytoskeleton and extracellular matrix } \\
\hline Myosin-13 & MYH13 & 208.8 & 5.6 & 21.5 & 5 & 1.68 & 1.21 \\
\hline Myosin-6 & MYH6 & 223.4 & 5.7 & 30.6 & 3 & 1.58 & 1.27 \\
\hline Myosin-4 & MYH4 & 222.7 & 5.7 & 30.5 & 4 & 1.56 & 1.18 \\
\hline Regulator of microtubule dynamics protein 1 & RMDN1 & 34.1 & 8.0 & 10.9 & 3 & 0.93 & 5.46 \\
\hline Tubulin alpha 6 & TUBA1C & 50.0 & 5.1 & 60.0 & 2 & 1.15 & 3.50 \\
\hline Tubulin beta- 3 chain & TUBB3 & 50.4 & 4.9 & 41.6 & 2 & 1.33 & 1.63 \\
\hline Myosin light chain kinase, smooth muscle & MYLK & 212.9 & 6.0 & 1.5 & 2 & 0.94 & 1.58 \\
\hline Fibrinogen beta chain & FGB & 54.2 & 7.8 & 13.4 & 5 & 1.37 & 1.65 \\
\hline Kinesin-like protein & KIF13B & 195.0 & 5.6 & 2.3 & 3 & 0.56 & 0.67 \\
\hline LIM domain binding 3 & LDB3 & 31.5 & 9.1 & 14.4 & 2 & 0.33 & 0.53 \\
\hline Collagen alpha-1(I) chain & COL1A1 & 137.5 & 5.6 & 21.0 & 24 & 0.40 & 0.56 \\
\hline Collagen type I alpha 2 & COL1A2 & 127.7 & 8.7 & 5.7 & 6 & 0.47 & 0.60 \\
\hline Alpha1 type II collagen & COL2A1 & 135.0 & 7.8 & 5.2 & 6 & 0.45 & 0.89 \\
\hline FERM domain containing-1 & FRMPD1 & 59.7 & 6.3 & 6.6 & 4 & 0.61 & 0.80 \\
\hline Alpha II-spectrin & SPTAN1 & 284.8 & 5.2 & 22.7 & 12 & 0.73 & 0.66 \\
\hline Immune response and cell death & & & & & & & \\
\hline D-dopachrome decarboxylase & DDT & 12.9 & 7.1 & 25.4 & 2 & 2.50 & 1.42 \\
\hline Complement component C3 & $\mathrm{C} 3$ & 45.6 & 7.1 & 13.6 & 4 & 1.73 & 1.96 \\
\hline Reticulon 3 & RTN3 & 24.5 & 9.0 & 13.1 & 2 & 1.72 & 1.62 \\
\hline Peroxiredoxin-2 & PRDX2 & 21.8 & 5.6 & 23.7 & 5 & 1.63 & 1.18 \\
\hline RAC-beta serine/threonine-protein kinase & AKT2 & 55.5 & 6.4 & 3.3 & 2 & 1.39 & 1.69 \\
\hline Stress-70 protein, mitochondrial & HSPA9 & 73.9 & 7.1 & 34.9 & 5 & 1.06 & 7.77 \\
\hline Heat shock protein 5 & HSPA5 & 71.9 & 5.1 & 49.7 & 6 & 0.89 & 6.01 \\
\hline Hemopexin & HPX & 51.0 & 6.6 & 30.0 & 12 & 0.88 & 3.06 \\
\hline Chaperone protein GP96 & HSP90B1 & 91.2 & 4.9 & 37.5 & 14 & 0.97 & 2.07 \\
\hline Superoxide dismutase $[\mathrm{Cu}-\mathrm{Zn}]$ & SOD1 & 15.9 & 6.6 & 64.9 & 8 & 0.63 & 1.91 \\
\hline Ferritin heavy chain & FTH1 & 21.1 & 6.3 & 39.0 & 5 & 1.34 & 1.57 \\
\hline Proteasome subunit alpha type & PSMA5 & 26.4 & 4.8 & 30.3 & 2 & 0.70 & 1.54 \\
\hline Proteasome activator complex subunit 2 & PSME2 & 26.8 & 5.7 & 28.2 & 2 & 0.90 & 0.61 \\
\hline Dynamin-like $120 \mathrm{kDa}$ protein, mitochondrial & OPA1 & 111.2 & 7.5 & 10.7 & 5 & 0.52 & 0.56 \\
\hline Proteasome subunit alpha type-1 & PSMA1 & 29.5 & 6.6 & 38.0 & 3 & 0.64 & 0.77 \\
\hline Oligosaccharyl transferase subunit DAD1 & DAD1 & 12.5 & 7.1 & 19.5 & 2 & 0.59 & 0.83 \\
\hline Proteasome subunit beta type- 7 & PSMB7 & 29.9 & 8.0 & 13.7 & 3 & 0.60 & 0.89 \\
\hline Death-associated protein 1 & DAP & 11.2 & 9.6 & 15.7 & 2 & 0.50 & 0.94 \\
\hline
\end{tabular}


TABLE 1 (CONTINUED)

PROTEOME ALTERATIONS IN THE REGENERATING NEWT LIMB IMMEDIATELY AFTER AMPUTATION

\begin{tabular}{|c|c|c|c|c|c|c|c|}
\hline Protein name & Genes & MW [kDa] & pl & Coverage & $\begin{array}{c}\text { Unique } \\
\text { Peptides }\end{array}$ & 2h/0h & $8 \mathrm{~h} / 0 \mathrm{~h}$ \\
\hline \multicolumn{8}{|l|}{ Carbohydrate, lipid, and energy metabolism } \\
\hline Acyl-coenzyme A thioesterase 12 & ACOT12 & 62.0 & 7.2 & 4.9 & 2 & 2.16 & 2.18 \\
\hline Pyruvate carboxylase & PC & 129.9 & 6.9 & 42.5 & 21 & 1.66 & 10.64 \\
\hline 24-hydroxycholesterol 7-alpha-hydroxylase & CYP39A1 & 48.0 & 9.1 & 7.6 & 3 & 1.93 & 1.35 \\
\hline ATP synthase subunit $f$, mitochondrial & ATP5J2 & 10.4 & 10.0 & 23.9 & 2 & 1.62 & 1.31 \\
\hline Glucose-6-phosphate 1-dehydrogenase & G6PD & 57.7 & 8.0 & 5.6 & 2 & 1.52 & 1.54 \\
\hline Very long-chain specific acyl-CoA dehydrogenase & ACADVL & 71.0 & 8.4 & 13.8 & 7 & 0.88 & 14.97 \\
\hline Phosphoglycerate kinase & PGK1 & 44.7 & 6.9 & 53.2 & 11 & 1.20 & 12.44 \\
\hline Glycogen synthase 2 & GYS2 & 80.5 & 6.6 & 5.0 & 3 & 0.69 & 7.88 \\
\hline Aldehyde dehydrogenase 2 family & ALDH2 & 56.5 & 6.3 & 45.5 & 6 & 1.26 & 6.75 \\
\hline Hydroxypyruvate isomerase & $\mathrm{HYI}$ & 31.0 & 5.6 & 10.5 & 3 & 0.97 & 6.59 \\
\hline Sterol carrier protein 2 & SCP2 & 57.9 & 7.4 & 20.1 & 6 & 1.01 & 4.73 \\
\hline Cellular retinol-binding protein type II & RBP2 & 15.8 & 6.5 & 37.0 & 4 & 1.07 & 4.01 \\
\hline Hydroxyacyl-Coenzyme A dehydrogenase beta subunit & HADHB & 49.9 & 9.2 & 27.6 & 2 & 0.86 & 3.22 \\
\hline Succinyl-CoA ligase [ADP/GDP-forming] subunit alpha, mitochondrial & SUCLG1 & 34.2 & 9.1 & 42.3 & 6 & 0.98 & 2.80 \\
\hline NADH dehydrogenase [ubiquinone] iron-sulfur protein 2 & NDUFS2 & 52.7 & 6.8 & 14.4 & 2 & 0.87 & 2.78 \\
\hline Isocitrate dehydrogenase [NAD] subunit, mitochondrial & IDH3G & 42.7 & 8.9 & 10.2 & 2 & 1.04 & 2.25 \\
\hline Acyl-Coenzyme A dehydrogenase & ACADM & 46.1 & 8.0 & 27.1 & 7 & 0.70 & 2.16 \\
\hline Pyruvate dehydrogenase E1 component subunit alpha & PDHA1 & 43.7 & 8.0 & 19.6 & 4 & 1.01 & 2.12 \\
\hline ATP-binding cassette, sub-family D (ALD), member 1 & ABCD1 & 81.9 & 8.5 & 4.3 & 2 & 0.88 & 2.02 \\
\hline 2-oxoglutarate dehydrogenase, mitochondrial & $\mathrm{OGDH}$ & 115.6 & 6.9 & 15.1 & 8 & 1.15 & 1.79 \\
\hline Protein Sec24a & SEC24A & 118.8 & 7.6 & 3.1 & 3 & 1.34 & 1.79 \\
\hline Oligosaccharyl transferase subunit STT3B & STT3B & 93.4 & 9.4 & 8.2 & 6 & 1.19 & 1.74 \\
\hline Glycerol-3-phosphate dehydrogenase 1 & GPD1 & 38.2 & 6.8 & 53.1 & 12 & 1.42 & 1.54 \\
\hline NADH dehydrogenase (Ubiquinone) 1 beta subcomplex 8 & NDUFB8 & 21.9 & 6.0 & 12.4 & 2 & 0.85 & 0.67 \\
\hline Ectonucleotide pyrophosphatase/phosphodiesterase 1 & ENPP1 & 102.8 & 6.6 & 10.4 & 7 & 0.95 & 0.65 \\
\hline Enolase & ENO1 & 17.1 & 9.0 & 37.9 & 4 & 0.86 & 0.62 \\
\hline Ethanolamine-phosphate cytidylyltransferase & РCYT2 & 45.2 & 6.7 & 14.1 & 5 & 0.70 & 0.59 \\
\hline Aldehyde dehydrogenase family 16 member $\mathrm{A} 1$ & ALDH16A1 & 85.4 & 6.2 & 3.7 & 2 & 0.61 & 0.68 \\
\hline Malic enzyme & ME1 & 64.5 & 7.3 & 20.2 & 9 & 0.59 & 0.66 \\
\hline Pyruvate dehydrogenase protein $X$ component & PDHX & 40.9 & 8.7 & 9.0 & 3 & 0.57 & 0.67 \\
\hline Transthyretin & TTR & 15.7 & 6.2 & 17.0 & 2 & 0.55 & 0.75 \\
\hline Carbohydrate kinase-like & SHPK & 50.6 & 5.9 & 8.7 & 3 & 0.53 & 0.61 \\
\hline Alkylglycerol monooxygenase & AGMO & 51.7 & 7.6 & 5.8 & 2 & 0.51 & 0.58 \\
\hline ATP synthase subunit beta & ATP5B & 46.1 & 5.1 & 44.0 & 2 & 0.50 & 0.56 \\
\hline ATP synthase subunit delta, mitochondrial & ATP5D & 17.6 & 5.2 & 13.7 & 2 & 0.49 & 0.64 \\
\hline Aflatoxin B1 aldehyde reductase member 3 & AKR7A3 & 36.5 & 6.7 & 16.7 & 4 & 0.40 & 0.74 \\
\hline 1,2-dihydroxy-3-keto-5-methylthiopentene dioxygenase & ADI1 & 21.4 & 5.4 & 21.2 & 3 & 1.51 & 1.23 \\
\hline \multicolumn{8}{|l|}{ Amino acid and purine metabolism } \\
\hline Aspartate aminotransferase & GOT2 & 47.6 & 9.2 & 45.3 & 14 & 1.14 & 19.45 \\
\hline Glycine N-methyltransferase & GNMT & 33.2 & 6.9 & 33.3 & 6 & 0.86 & 7.14 \\
\hline Sarcosine dehydrogenase, mitochondrial & SARDH & 102.8 & 7.2 & 19.4 & 4 & 1.11 & 5.71 \\
\hline 4-aminobutyrate aminotransferase & ABAT & 55.7 & 7.7 & 35.6 & 12 & 1.15 & 4.23 \\
\hline Alanine aminotransferase 2 & GPT2 & 61.1 & 8.3 & 46.5 & 14 & 1.11 & 4.07 \\
\hline Serine hydroxymethyltransferase & SHMT1 & 53.3 & 7.9 & 39.1 & 12 & 1.05 & 3.90 \\
\hline Purine nucleoside phosphorylase & PNP & 33.8 & 7.0 & 25.0 & 4 & 0.92 & 2.88 \\
\hline Formimidoyltransferase-cyclodeaminase & FTCD & 60.3 & 7.0 & 40.0 & 18 & 1.11 & 2.68 \\
\hline 2-amino-3-ketobutyrate coenzyme A ligase & GCAT & 49.6 & 8.1 & 30.4 & 11 & 0.85 & 2.50 \\
\hline 3-hydroxyanthranilate 3,4-dioxygenase & HAAO & 33.2 & 5.7 & 31.7 & 8 & 0.80 & 1.85 \\
\hline Nucleoside diphosphate kinase, mitochondrial & NME4 & 21.2 & 9.7 & 46.3 & 8 & 1.35 & 1.59 \\
\hline Nucleoside diphosphate kinase B & NME2 & 17.3 & 7.4 & 67.8 & 3 & 1.20 & 1.54 \\
\hline Nucleoside diphosphate kinase DR-nm23 & NME3 & 19.1 & 6.3 & 28.4 & 3 & 1.31 & 1.52 \\
\hline Gamma-glutamylaminecyclotransferase & GGACT & 16.9 & 6.5 & 20.1 & 2 & 0.72 & 0.65 \\
\hline 4-hydroxyphenylpyruvate dioxygenase & HPD & 45.2 & 6.8 & 57.9 & 2 & 1.11 & 0.64 \\
\hline Endoplasmic reticulum metallopeptidase 1 & ERMP1 & 99.9 & 7.5 & 3.7 & 3 & 0.58 & 0.55 \\
\hline
\end{tabular}

pathways were significantly changed at $2 \mathrm{~h}$ and $8 \mathrm{~h}$ after amputation, including EIF2 signaling, acute phase response signaling, tight junction signaling, protein ubiquitination pathway, calcium signaling, endoplasmic reticulum stress pathway and PI3K/AKT signaling, indicating that these pathways play predominant roles at the very early phase of newt limb regeneration (Fig. 4). A detailed pathway enrichment of the differentially expressed proteins at the very early phase of newt limb regeneration was provided in Supplementary Table 2.

\section{Discussion}

ITRAQ coupled with LC-MS/MS method is rapid and more sensitive than many other proteomic methods, and increases the protein dynamic range of threefold to fourfold compared to twodimensional gel electrophoresis. Therefore, we used this method to examine the protein expression changes in the regenerating newt limbs immediately after amputation, and found that 152 proteins were significantly altered at $2 \mathrm{~h}$ and $8 \mathrm{~h}$ after amputation. Based on these results, we could ratiocinate that the fluctuation in protein level immediately after amputation was associated with adaptive response in newt limb regeneration, such as immune response, cell death and metabolism.

\section{Signaling, $\mathrm{Ca}^{2+}$ binding and translocation}

It has been reported that limb amputation causes a major increase in the level of cytosolic $\mathrm{Ca}^{2+}$, and calcium signaling is essential for newt limb regeneration in the axolotl (Globus et al., 1987, Rao et al., 2009). Consistent with this result, we also found that calcium signaling was significantly changed at the very early phase of newt limb regeneration. In addition, $\mathrm{Ca}^{2+}$-binding protein S100A10 was up-regulated at $2 \mathrm{~h}$ and $8 \mathrm{~h}$ after amputation of the newt limb, in harmony with studies showing that the expression level of several S100 family $\mathrm{Ca}^{2+}$-binding proteins were enhanced in the 
A

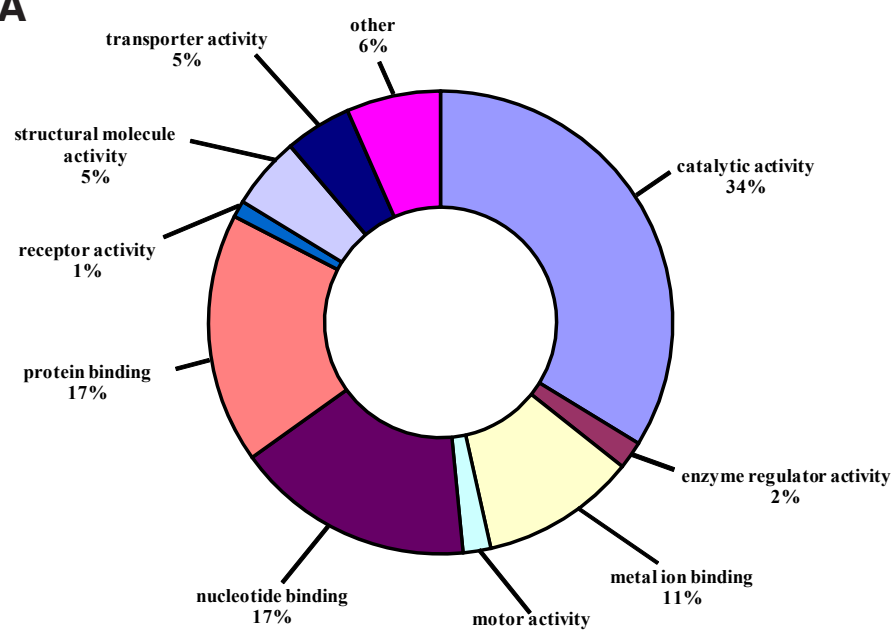

B

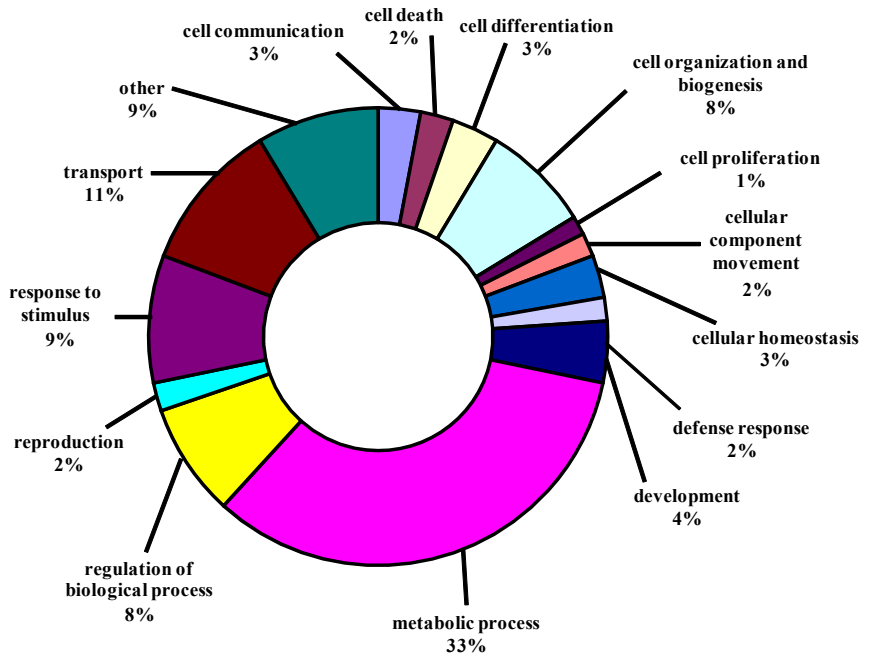

Fig. 3. Functional and cellular categorization of proteins. Pie charts showing categories of 152 proteins according to (A) molecular function and (B) biological process.

regenerating ear tissue of MRL/Mpj-Fas mice and in regenerationcompetent stage 53 Xenopus limb buds (Caldwell et al., 2008, King et al., 2009). Moreover, other $\mathrm{Ca}^{2+}$-binding proteins such as ryanodine receptor and ATP2A1 were up-regulated. Ryanodine receptor is involved in skeletal muscle contraction by releasing calcium from the sarcoplasmic reticulum followed by depolarization of T-tubules (Sei et al., 1999). ATP2A1 is intracellular pump located in the sarcoplasmic or endoplasmic reticula of muscle cells and is also involved in muscle contraction. These results suggest that calcium signaling is a key event at the very early phase of newt limb regeneration.

Annexins, calcium-dependent phospholipid-binding proteins with various biological processes, were detected in the regenerating limbs of both axolotl and froglet, and might be important for histolysis during limb regeneration (Menaa et al., 1999, Rao et al., 2014). In the present study, the protein ubiquitination pathway essential for histolysis was significantly changed at the very early phase of newt limb regeneration. In addition, annexin 2 was found to be up-regulated at $2 \mathrm{~h}$ after amputation, consistent with the finding that the expression level of annexin 2 was significantly increased in the regenerating amphibian limbs (King et al., 2009, Rao et al., 2009), suggesting that annexin 2 plays an important role in newt limb regeneration.

Rab family GTPases play a critical role in regulating intracellular vesicle trafficking of proteins (Takai et al., 2001). Several Rab family GTPases and their activators and exchangers were found to be differentially regulated in the regenerating axolotl limb after amputation (Rao et al., 2009). In this study, RAB10 belonging to the RAS superfamily of small GTPases was differentially expressed at $2 \mathrm{~h}$ after amputation of newt limb. In addition, RANGAP1 was critically involved in smooth muscle cell differentiation, proliferation and migration following vascular injury (Vorpahl et al., 2014), and was found to be up-regulated at $2 \mathrm{~h}$ after amputation of newt limb. These results indicate that proteins associated with $\mathrm{Ca}^{2+}$ binding and translocation are predominant during newt limb regeneration.

\section{Transcription and translation}

Studies have indicated that both RNA and protein synthesis are enhanced during blastema formation of limb regeneration (Morzlock and Stocum, 1971, Tsonis et al., 1992). DDX39A belonging a member of the DEAD box protein family, was up-regulated at the very early phase of newt limb regeneration, and implicated in a number of cellular processes such as translation initiation and the assembly of ribosome and spliceosome. Study has reported that tRNA aminoacylation-related protein TARSL2 was up-regulated at 1 day after amputation (Rao et al., 2009), and we found another tRNA aminoacylation-related protein CARS was up-regulated at $2 \mathrm{~h}$ and $8 \mathrm{~h}$ after amputation. In addition, the expression level of SF3B2 for mRNA splicing was increased at $8 \mathrm{~h}$. The results indicate that mRNA processing is a critical for controlling protein synthesis during blastema formation, which was confirmed by a report previously published (Rao et al., 2009).

However, most of ribosomal proteins and translation initiation factors were decreased in expression level, in accordance with the findings that initiation factors was down-regulated at 1 day after amputation of axolotl limb (Rao et al., 2009). Meantime, EIF2 signaling and eIF4 and p70S6K signaling associated with translation was significantly changed at the very early phase of newt limb regeneration. Our data suggest that the differentially expressed proteins involved in the transcriptional and translational machinery are available for whatever protein synthesis is required during newt limb regeneration.

\section{Cytoskeleton and extracellular matrix}

Mononucleate cells from cellularization of myofibers underwent dedifferentiation after amputation of limb (Brockes and Kumar, 2002). A study reported that wound closure in planarians after amputation was facilitated by muscle contraction (Handberg-Thorsager et al., 2008). We found that muscle contraction-related proteins $\mathrm{MYH} 4, \mathrm{MYH} 6$ and MYH13 were up-regulated at $2 \mathrm{~h}$, and MYLK was up-regulated at $8 \mathrm{~h}$. The gradual up-regulation of proteins related to motility, shape and structural integrity was observed at 4 and 7 day after amputation of axolotl limb (Rao et al., 2009), which is consistent with our result that the expression level of microtubule proteins TUBB3, TUBA1C and RMDN1 were increased at $8 \mathrm{~h}$ after amputation. TUBB3 was primarily expressed in neurons and might 
be involved in neurogenesis and axon guidance and maintenance which were important for limb regeneration. Furthermore, this study found that several signaling pathways associated with the migration of cells into the wound site were significantly enriched by IPA analysis, such as epithetial adherens junction signaling, tight junction signaling, actin cytoskeleton signaling, and ILK signaling, which were also found to participate in regulating the initiation of planarian head regeneration by our previous study (Geng et al., $2015 b)$. These results indicate that epidermal cells might migrate to close the wound through the above mentioned pathways.

With regard to extracellular matrix proteins, we found that the regenerating newt limbs up-regulated fibrinogen and downregulated type II collagen, which is consistent with the findings that the Xenopus and axolotl limbs up-regulated fibrinogen, and downregulated type II collagen (Rao et al., 2014). The result indicates that the regenerating limb presents a trend toward expression of a less structured matrix.

\section{Immune response and cell death}

Amputation results in tremendous systemic and cellular stress. A major result of cell stress is hypoxia-induced apoptosis (Mescher, 1996). A previous study reported that immediate early response was induced at $2 \mathrm{~h}$ post injury of newt heart, and first signals of inflammatory cell recruitment and initiation of cell death happened at $6 \mathrm{~h}$ post injury of newt heart (Looso et al., 2013). Similar with this result, our IPAanalysis showed that acute phase response signaling was significantly changed at $2 \mathrm{~h}$ and $8 \mathrm{~h}$ after amputation. Another study reported that cell apoptosis increased in regenerating axolotl limbs immediately after amputation and gradually reduced, and little cell apoptosis was observed on 4 and 7 day, suggesting that cell stress caused by amputation gradually activates anti-apoptosis mechanism during limb regeneration (Rao et al., 2009).

The limb after amputation countered the stress through in- creasing protein degradation by proteasomes mechanisms, and through the up-regulation expression of chaperones to promote protein folding in the endoplasmic reticulum. Failure to remove the misfolded proteins from the endoplasmic reticulum resulted in apoptosis. IPA analysis showed that endoplasmic reticulum stress was significantly changed at the very early phase of newt limb regeneration, suggesting cell stress response is induced by amputation. Heat shock proteins play crucial roles in the modulation of pathways regulating stem cell activity, regeneration and tissue repair (Isolani et al., 2012). The up-regulation of molecular chaperone HSP90B1 and heat shock proteins HSPA5 and HSPA9 were observed in our study, being consistent with the findings that the level of chaperone genes was increased in the regenerating newt and axolotl limbs (Levesque et al., 2005, Monaghan et al., 2009), Xenopus laevis hindlimbs (Pearl et al., 2008). The results indicate that the regenerating limb has some protection against the stress response through through the up-regulation expression of chaperones.

It was reported that proteolysis by several proteases is crucial for regulating intestinal regeneration in Holothuria glaberrima (Pasten et al., 2012). We found that three of four proteasome proteins were down-regulated by iTRAQ quantitative analysis. The result suggests that the regenerating limb has a degree of resistance to stress, but is inadequate to counter the stress response at the very early phase, leading to a slight increase of apoptosis at the very early phase of newt limb regeneration. Our result was consistent with the findings of Vlaskalin et al., (Vlaskalin et al., 2004) who observed that there was a massive apoptosis in the adult newt forelimbs within the first 3 days post-amputation which did not appear to be present in the axolotl forelimbs, probably due to the fact that cells in the forelimb of the larval axolotl were not fully differentiated.

The vertebrate immune system comprises both adaptive and innate immune cells with distinct functions during the resolution

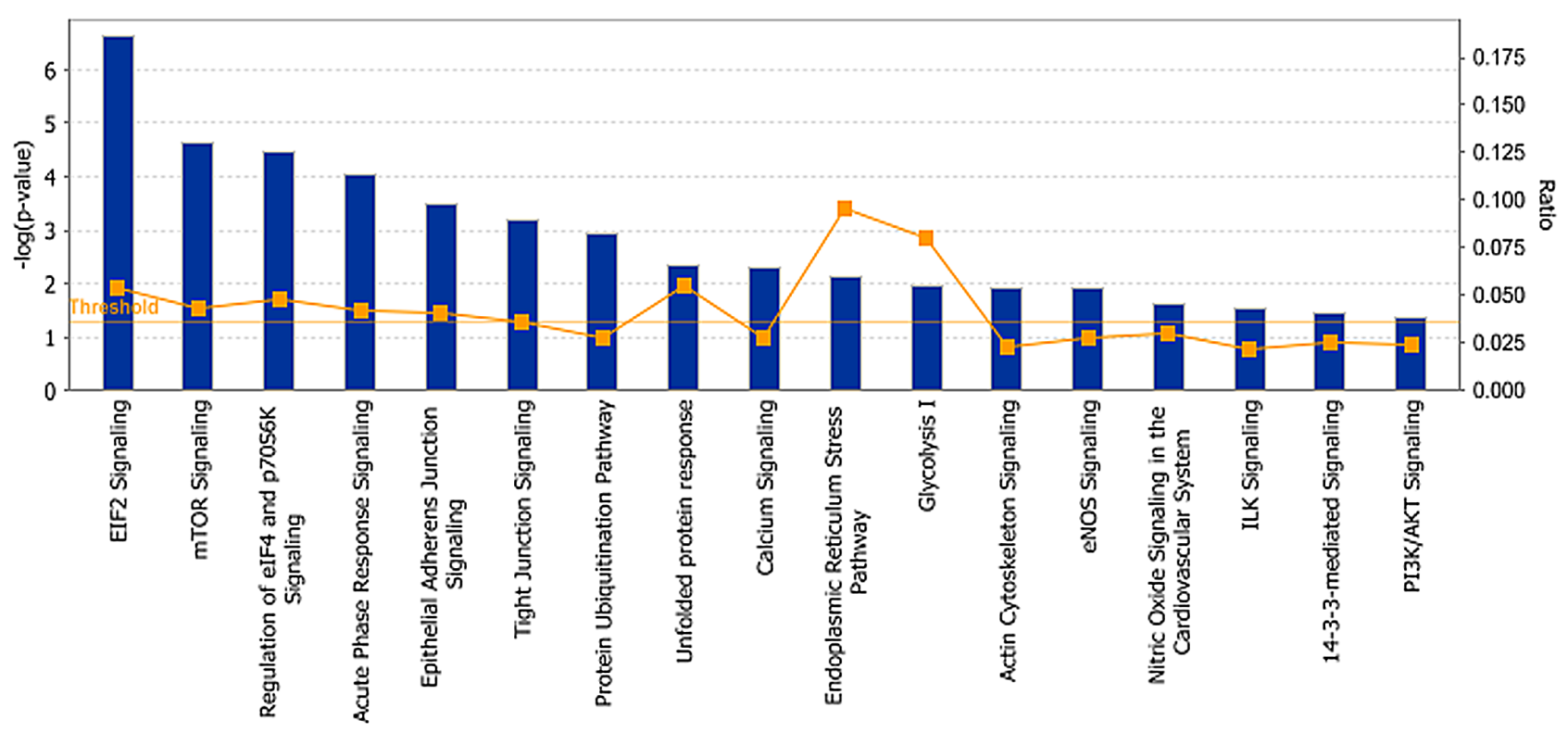

Fig. 4. The significantly enriched canonical pathways at the very early phase of newt limb regeneration by IPA software. Each histogram is a particular canonical pathway. The size of the histogram is correlated with increasing overlap significance (Fisher's exact test p-value). Ratio value represents the number of focus molecules to overall molecules in each canonical pathway. 
of inflammation and wound healing after tissue injury (King et al., 2012, Mescher et al., 2013). Recent evidence implicates a requirement for innate immune cells from the myeloid lineage during the early stages of limb regeneration in the Mexican axolotl (Godwin et al., 2013). Previous studies reported that the C3 and C5 proteins were expressed in a complementary fashion during limb regeneration, with $\mathrm{C} 3$ being expressed mainly in the blastema and C5 exclusively in the wound epithelium (Del RioTsonis et al., 1998, Kimura et al., 2003). In the present study, the up-regulation expression of complement component C3 was observed in the regenerating newt limb immediately after amputation. These results indicate that C3 is implicated in the dedifferentiation process, and immune response plays important roles in newt limb regeneration.

\section{Metabolism}

It was found that the regenerating tissue exhibited the Warburg effect, and the early blastema relied on anaerobic glycolysis or alternate pathways such as the pentose phosphate shunt and lipid metabolism to maintain ATP production (Naviaux et al., 2009). A recent study reported that carbohydrate regulatory genes played an essential role during Xenopus tadpole tail appendage regeneration by stimulating the anabolic pathways required for the reconstruction of a new appendage (Love et al., 2014). Our data showed that glycolysis-related proteins (PGK and GPD1) and fatty acid oxidation-related proteins (ACADM, ACADVL and HADHB) were found to be up-regulated at $8 \mathrm{~h}$ after amputation. In addition, several enzymes of tricarboxylic acid cycle, electron transport chain and oxidative phosphorylation were down-regulated in the regenerating newt limb immediately after amputation, including PDHX, NDUFB8, ATP5B and ATP5D. These studies indicate that the limb regeneration immediately after amputation mainly relied on glycolysis and fatty acid oxidation to maintain ATP production, consistent with previous study showing a marked decrease in $\mathrm{O}_{2}$ usage during early stage of urodele limb regeneration (Rao et al., 2009, Rao et al., 2014).

The iron-binding molecule transferrin is essential for mitosis in the axolotl blastema (Mescher et al., 1997), and was downregulated in the regenerating newt limb immediately after amputation, indicating that the regenerating limb does not exhibit significant mitosis until the accumulation blastema has formed, whereas mitotic index is as high as $10 \%$ in the blastema at 3 day after amputation (Cannata et al., 1992).

\section{Conclusions}

The advanced proteomic technology iTRAQ was utilized to detect the proteomes in the regenerating newt limb at $2 \mathrm{~h}$ and $8 \mathrm{~h}$ after amputation. In total 152 significantly differentially expressed proteins were identified in our study. Functional annotation found that these proteins were mainly involved in several functional categories including signaling, $\mathrm{Ca}^{2+}$ binding and translocation, translation, immune response, apoptosis and metabolism. Further IPA analysis showed that several signaling pathways including acute phase response signaling and calcium signaling maybe closely related to the adaptive response immediately after limb amputation. This work provides a basis for further study of regenerative medicine.

\section{Materials \& Methods}

Model preparation of Chinese fire-bellied newt limb regeneration Chinese fire-bellied newts (Cynops orientalis) were collected from Jigong Mountain of Xinyang, Henan province, China. A total of 15 well-grown adult Chinese fire-bellied newts were randomly divided into one control group and two experimental groups with 5 Chinese fire-bellied newts per group. The forelimbs of Chinese fire-bellied newts were amputated in distal portion of stylopod (Humerus) on the right side. The distal tissue with $2 \mathrm{~mm}$ was removed at the amputation site and was served as control group. The regenerating tissues with $2 \mathrm{~mm}$ in each group were collected at $2 \mathrm{~h}$ and $8 \mathrm{~h}$ after amputation, respectively. The samples were stored in liquid nitrogen for further use. All experiments were performed in strict accordance with the Animal Protection Law of China.

\section{Protein extraction and ITRAQ labeling}

Protein extraction was performed using a procedure described previously (Geng et al., 2014). Briefly, the frozen regenerating tissues were grinded into fine powder in liquid nitrogen. Then the tissue powder was lysed, and vortexed at $4^{\circ} \mathrm{C}$ for $1 \mathrm{~h}$. Subsequently, the mixture was centrifuged at 20000 $\mathrm{g}$ for $1 \mathrm{~h}$ at $4^{\circ} \mathrm{C}$. The supernatant was collected and stored at $-80^{\circ} \mathrm{C}$ until further analysis. The concentration of protein was determined using a $2 \mathrm{D}$ Quantification kit (GE Healthcare, USA).

A total of $200 \mu \mathrm{g}$ of each protein sample was denatured, reduced and alkylated as described in the iTRAQ protocol (Applied Biosystems). Each sample was digested with $0.1 \mu \mathrm{g} / \mu \mathrm{L}$ trypsin solution at $37^{\circ} \mathrm{C}$ overnight. The digested peptides were dried by vacuum centrifugation. Then the 118, 119 and 121 tags were respectively utilized to label the tryptic peptides from control $(0 \mathrm{~h}), 2 \mathrm{~h}$ and $6 \mathrm{~h}$ samples. Subsequently, the iTRAQ labeled peptides were pooled and vacuum-dried.

\section{Strong cation exchange (SCX) chromatography}

Strong cation exchange chromatography was performed according to the method previously described (Geng et al., 2015a, Geng et al., 2015b). Briefly, the pooled sample was separated on the Poly-LC strong cation exchange column $(4.6 \times 100 \mathrm{~mm})(5 \mu \mathrm{m}, 200 \AA)$ using AKTA Purifier 100 (GE Healthcare). The peptides were injected into a liquid SCX chromatography at a flow rate of $0.07 \mathrm{~mL} / \mathrm{min}$. Subsequently, the peptides were gradiently eluted at a flow rate of $1 \mathrm{~mL} / \mathrm{min}$ with $10 \%$ buffer $\mathrm{B}\left(10 \mathrm{mM} \mathrm{KH}_{2} \mathrm{PO}_{4}, 500\right.$ $\mathrm{mM} \mathrm{KCl}, 25 \%$ acetonitrile, $\mathrm{pH} 3.0$ ) for $7 \mathrm{~min}, 10-20 \%$ buffer $\mathrm{B}$ for $10 \mathrm{~min}$, $20-45 \%$ buffer B for $5 \mathrm{~min}, 45-100 \%$ buffer B for $5 \mathrm{~min}$. Finally, the system was maintained at $100 \%$ buffer $B$ for $8 \mathrm{~min}$. A total of 30 fractions were collected over the gradient, but some were pooled to give a final total of 10 fractions that were desalted using a PepClean C-18 spin column (Sigma, USA), and dried by vacuum centrifugation (Nicholson et al., 2012).

\section{LC-MS/MS analysis for protein identification}

Protein identification by mass spectrometry was performed according to the method previously described (Hsieh et al., 2009). In brief, each fraction was injected into Thermo scientific EASY column $(75 \mu \mathrm{m} \times 100 \mathrm{~mm}$, $3 \mu \mathrm{m}-\mathrm{C} 18)$, and then was separated on Thermo scientific EASY column (2cm x 100 $\mu \mathrm{m}, 5 \mu \mathrm{m}-\mathrm{C} 18)$ using Thermo Scientific EASY-nLC 1000 system. Subsequently, the separated samples by capillary high performance liquid chromatography were analyzed by $\mathrm{Q}$-Exactive mass spectrometer (Thermo Fisher Scientific, Waltham, MA, USA) (Geng et al., 2015a, Geng et al., 2015b, Hsieh et al., 2009, Nicholson et al., 2012).

\section{Data analysis}

For peptide data analysis, raw mass data were processed using Proteome Discover 1.4 software and searched against the SwissProt database (March 2013) from Uniprot website (http://www.uniprot.org) using Mascot 2.2 (Matrix Science, London, UK). The analysis and search parameters were set as follows: trypsin as the digestion enzyme with allowance for a maximum of two missed cleavage, Carbamidomethyl (C) and iTRAQplex 
modification( $\mathrm{K}$ and $\mathrm{N}$-terminus) as a fixed modification, Oxidation (M) as a variable modifications, peptide mass tolerance of 20ppm, fragment mass tolerance of 0.1 Da (Geng et al., 2015a, Geng et al., 2015b).

In order to measure the false discovery rate (FDR), the peptide mass spectra datasets were used to search a decoy peptide database. The following filters were used in this study, peptide FDR $\leq 0.01$ and each protein with at least 2 unique peptides. Expression changes of the identified peptides in the regenerating head fragments were calculated in comparison with the control based on the ITRAQ reporter ion intensities (Unwin et al., 2010). Only unique peptides were utilized to determine protein quantification. In this study, we utilized the frequency distribution histogram to analyze the iTRAQ quantitative data. We firstly calculated the protein ratio by comparing its relative expression level in experimental group to that in normal control group. Then, we calculated a significance score (P-value) for log protein ratios using the method previously published (Cox and Mann, 2008), and the significance score represented the probability of obtaining a log-ratio of at least this magnitude under the null hypothesis that the distribution of log-ratios has normal upper and lower tails. Based on relative quantification and statistical analysis, 1.5 -fold change cutoff was selected to categorize proteins as significantly changed, that is, proteins with iTRAQ ratios $>1.5$ were considered to be up-regulated, whereas those with iTRAQ ratios < 0.67 were considered to be down-regulated.

\section{Bioinformatics analysis}

In order to characterize the expression patterns of the proteins identified in our quantitative ITRAQ data, Cluster 3.0/TreeView software was used for hierarchical clustering of the differentially expressed proteins as described in detail previously (Geng et al., 2015c).

Gene Ontology (GO) annotation was used to determine the biological processes of the proteins. In addition, the differentially expressed proteins were analyzed by Ingenuity Pathway Analysis (IPA) version 9.0 (Redwood City, CA, http://www.ingenuity.com) software for predominant canonical pathways according to the method previously published (Geng et al., 2015a, Geng et al., 2015b). Briefly, a dataset containing these proteins and corresponding extremum of expression values was firstly uploaded into "Dataset Files" of the IPA. Then the proteins were performed by core analysis in IPA. Canonical pathways obtained in this study were identified from the IPA library based on Fisher's Exact Test $P$-value. In this study, pathways with $P$-value $<0.05$ were chosen to be predominant at the very early phase of newt limb regeneration.

\section{Acknowledgements}

This work was supported by grants from the National Basic Research 973 Pre-research Program of China (No. 2012CB722304), Natural Science Foundation of China (No. 31572270), the Major Scientific and Technological Projects of Henan (No. 111100910600), the Foundation and Advanced Technology Research Program of Henan (No. 112300413204), and the doctoral Scientific Research Start-up Foundation of Henan Normal University (No. QD14176).

\section{References}

BROCKES J P and KUMAR A (2002). Plasticity and reprogramming of differentiated cells in amphibian regeneration. Nat Rev Mol Cell Biol 3: 566-574.

BRYANT S V, ENDO T and GARDINER D M (2002). Vertebrate limb regeneration and the origin of limb stem cells. Int J Dev Biol 46: 887-896.

CALDWELL R L, OPALENIK S R, DAVIDSON J M, CAPRIOLI R M and NANNEY L $B$ (2008). Tissue profiling MALDI mass spectrometry reveals prominent calciumbinding proteins in the proteome of regenerative MRL mouse wounds. Wound Repair Regen 16: 442-449.

CANNATA S M, BERNARDINI S and FILONI S (1992). Regenerative responses in cultured hindlimb stumps of larval Xenopus laevis. $J$ Exp Zool 262: 446-453.

COX J and MANN M (2008). MaxQuant enables high peptide identification rates, individualized p.p.b.-range mass accuracies and proteome-wide protein quantification. Nat Biotechnol 26: 1367-1372.
DEL RIO-TSONIS K, TSONIS P A, ZARKADIS I K, TSAGAS A G and LAMBRIS J D (1998). Expression of the third component of complement, $\mathrm{C} 3$, in regenerating limb blastema cells of urodeles. J Immunol 161: 6819-6824.

GENG X, CHANG C, ZANG X, SUN J, LI P, GUO J and XU C (2016). Integrative proteomic and microRNA analysis of the priming phase during rat liver regeneration. Gene 575: 224-232 (doi: 10.1016/j.gene.2015.08.066).

GENG X, WANG G, QIN Y, ZANG X, LI P, GENG Z, XUE D, DONG Z, MA K, CHEN $G$ et al., (2015b). iTRAQ-Based Quantitative Proteomic Analysis of the Initiation of Head Regeneration in Planarians. PLoS One 10: e0132045.

GENG $X$, WEI H, SHANG H, ZHOU M, CHEN B, ZHANG F, ZANG X, LI P, SUN J, CHE J et al., (2015c). Proteomic analysis of the skin of Chinese giant salamander (Andrias davidianus). J Proteomics 119: 196-208.

GENG X, XU T, NIU Z, ZHOU X, ZHAO L, XIE Z, XUE D, ZHANG F and XU C (2014). Differential proteome analysis of the cell differentiation regulated by $\mathrm{BCC}, \mathrm{CRH}$, CXCR4, GnRH, GPCR, IL1 signaling pathways in Chinese fire-bellied newt limb regeneration. Differentiation 88: 85-96.

GLOBUS M, VETHAMANY-GLOBUS S and KESIKA (1987). Control of blastema cell proliferation by possible interplay of calcium and cyclic nucleotides during newt limb regeneration. Differentiation 35: 94-99.

GODWIN J W, PINTO A R and ROSENTHAL N A (2013). Macrophages are required for adult salamander limb regeneration. Proc Natl Acad Sci U SA 110: 9415-9420.

GROW M, NEFF A W, MESCHER A L and KING M W (2006). Global analysis of gene expression in Xenopus hindlimbs during stage-dependent complete and incomplete regeneration. Dev Dyn 235: 2667-2685.

HANDBERG-THORSAGER M, FERNANDEZ E and SALO E (2008). Stem cells and regeneration in planarians. Front Biosci 13: 6374-6394.

HSIEH H C, CHEN Y T, LI J M, CHOU T Y, CHANG M F, HUANG S C, TSENG T L, LIU C C and CHEN S F (2009). Protein profilings in mouse liver regeneration after partial hepatectomy using iTRAQ technology. J Proteome Res 8: 1004-1013.

ISOLANI M E, CONTE M, DERI P and BATISTONI R (2012). Stem cell protection mechanisms in planarians: the role of some heat shock genes. Int $J$ Dev Biol 56: 127-133.

ITEN L E and BRYANT S V (1973). Forelimb Regeneration from Different Levels of Amputation in the Newt, Notophthalmus viridescens: Length, Rate, and Stages. Wilhelm Roux'Arehiv 173: 263-282.

KIMURA Y, MADHAVAN M, CALL M K, SANTIAGO W, TSONIS P A, LAMBRIS J D and DEL RIO-TSONIS K (2003). Expression of complement 3 and complement 5 in newt limb and lens regeneration. J Immunol 170: 2331-2339.

KING M W, NEFF A W and MESCHER A L (2009). Proteomics analysis of regenerating amphibian limbs: changes during the onset of regeneration. Int $J$ Dev Biol 53: $955-969$

KING M W, NEFF A W and MESCHER A L (2012). The developing Xenopus limb as a model for studies on the balance between inflammation and regeneration. Anat Rec (Hoboken) 295: 1552-1561.

KUMAR A, GODWIN J W, GATES P B, GARZA-GARCIA A A and BROCKES J P (2007). Molecular basis for the nerve dependence of limb regeneration in an adult vertebrate. Science 318: 772-777.

LEVESQUE M, GUIMOND J C, PILOTE M, LECLERC S, MOLDOVAN F and ROY $S$ (2005). Expression of heat-shock protein 70 during limb development and regeneration in the axolotl. Dev Dyn 233: 1525-1534.

LOOSO M, PREUSSNER J, SOUSOUNIS K, BRUCKSKOTTEN M, MICHEL C S, LIGNELLI E, REINHARDT R, HOFFNER S, KRUGER M, TSONIS P A et al., (2013). A de novo assembly of the newt transcriptome combined with proteomic validation identifies new protein families expressed during tissue regeneration. Genome Biol 14: R16.

LOVE N R, ZIEGLER M, CHEN Y and AMAYA E (2014). Carbohydrate metabolism during vertebrate appendage regeneration: what is its role? How is it regulated? A postulation that regenerating vertebrate appendages facilitate glycolytic and pentose phosphate pathways to fuel macromolecule biosynthesis. Bioessays 36: 27-33.

MENAA C, DEVLIN R D, REDDY S V, GAZITT Y, CHOI S J and ROODMAN G D (1999). Annexin II increases osteoclast formation by stimulating the proliferation of osteoclast precursors in human marrow cultures. J Clin Invest 103: 1605-1613.

MESCHER A L (1996). The cellular basis of limb regeneration in urodeles. Int J Dev Biol 40: 785-795.

MESCHER A L, CONNELL E, HSU C, PATEL C and OVERTON B (1997). Transfer- 
rin is necessary and sufficient for the neural effect on growth in amphibian limb regeneration blastemas. Dev Growth Differ 39: 677-684.

MESCHER A L, NEFF A W and KING M W (2013). Changes in the inflammatory response to injury and its resolution during the loss of regenerative capacity in developing Xenopus limbs. PLoS One 8: e80477.

MONAGHAN J R, EPP LG, PUTTAS, PAGE RB, WALKER JA, BEACHYCK, ZHUW, PAO G M, VERMA I M, HUNTER T et al., (2009). Microarray and cDNA sequence analysis of transcription during nerve-dependent limb regeneration. BMCBiol7: 1 .

MORRISON J I, LOOF S, HE P and SIMON A (2006). Salamander limb regeneration involves the activation of a multipotent skeletal muscle satellite cell population. J Cell Biol 172: 433-440.

MORZLOCK F V and STOCUM D L (1971). Patterns of RNA synthesis in regenerating limbs of the adult newt, Triturus viridescens. Dev Biol 24: 106-118.

NAVIAUX R K, LE T P, BEDELBAEVA K, LEFEROVICH J, GOUREVITCH D, SACHADYNP, ZHANG XM, CLARK L and HEBER-KATZE (2009). Retained features of embryonic metabolism in the adult MRL mouse. Mol Genet Metab 96: 133-144.

NICHOLSON J, NEELAGANDAN K, HUART A S, BALL K, MOLLOY M P and HUPP $T$ (2012). An iTRAQ proteomics screen reveals the effects of the MDM2 binding ligand Nutlin-3 on cellular proteostasis. J Proteome Res 11: 5464-5478.

NYE H L, CAMERON J A, CHERNOFF E A and STOCUM D L (2003). Regeneration of the urodele limb: a review. Dev Dyn 226: 280-294.

PASTEN C, ROSA R, ORTIZ S, GONZALEZ S and GARCIA-ARRARAS J E (2012). Characterization of proteolytic activities during intestinal regeneration of the sea cucumber, Holothuria glaberrima. Int J Dev Biol 56: 681-691.

PEARL E J, BARKER D, DAY R C and BECK C W (2008). Identification of genes associated with regenerative success of Xenopus laevis hindlimbs. BMC Dev Biol 8: 66.

RAO N, JHAMB D, MILNER D J, LI B, SONG F, WANG M, VOSS S R, PALAKAL M, KING M W, SARANJAMI B et al., (2009). Proteomic analysis of blastema formation in regenerating axolotl limbs. $B M C$ Biol 7: 83
RAO N, SONG F, JHAMB D, WANG M, MILNER D J, PRICE N M, BELECKY-ADAMS T L, PALAKAL M J, CAMERON J A, LI B et al., (2014). Proteomic analysis of fibroblastema formation in regenerating hind limbs of Xenopus laevis froglets and comparison to axolotl. BMC Dev Biol 14: 32.

SEI Y, GALLAGHER K L and BASILE A S (1999). Skeletal muscle type ryanodine receptor is involved in calcium signaling in human $\mathrm{B}$ lymphocytes. $J$ Biol Chem 274: 5995-6002

TAKAI Y, SASAKI T and MATOZAKI T (2001). Small GTP-binding proteins. Physiol Rev 81: 153-208.

TSONIS PA(1993). A comparative two-dimensional gel protein database of the intact and regenerating newt limbs. Electrophoresis 14: 148-156.

TSONIS PA, MESCHER A L and DEL RIO-TSONIS K (1992). Protein synthesis in the newt regenerating limb. Comparative two-dimensional PAGE, computer analysis and protein sequencing. Biochem $J$ 281: 665-668.

UNWIN R D, GRIFFITHS J R and WHETTON A D (2010). Simultaneous analysis of relative protein expression levels across multiple samples using ITRAQ isobaric tags with 2D nano LC-MS/MS. Nat Protoc 5: 1574-1582.

VASCOTTO S G, BEUG S, LIVERSAGE R A and TSILFIDIS C (2005). Identification of cDNAs associated with late dedifferentiation in adult newt forelimb regeneration. Dev Dyn 233: 347-355

VLASKALIN T, WONG C J and TSILFIDIS C (2004). Growth and apoptosis during larval forelimb development and adult forelimb regeneration in the newt (Notophthalmus viridescens). Dev Genes Evol 214: 423-431.

VORPAHL M, SCHONHOFER-MERL S, MICHAELIS C, FLOTHO A, MELCHIOR $F$ and WESSELY R (2014). The Ran GTPase-activating protein (RanGAP1) is critically involved in smooth muscle cell differentiation, proliferation and migration following vascular injury: implications for neointima formation and restenosis. PLoS One 9: e101519.

WU C H, TSAI M H, HO C C, CHEN C Y and LEE H S (2013). De novo transcriptome sequencing of axolotl blastema for identification of differentially expressed genes during limb regeneration. BMC Genomics 14: 434 


\section{Further Related Reading, published previously in the Int. J. Dev. Biol.}

Characterization of proteolytic activities during intestinal regeneration of the sea cucumber, Holothuria glaberrima Consuelo Pasten, Rey Rosa, Stephanie Ortiz, Sebastián González and José E. García-Arrarás Int. J. Dev. Biol. (2012) 56: 681-691

http://dx.doi.org/10.1387/ijdb.113473cp

Stem cell protection mechanisms in planarians: the role of some heat shock genes Maria-Emilia Isolani, Maria Conte, Paolo Deri and Renata Batistoni

Int. J. Dev. Biol. (2012) 56: 127-133

http://dx.doi.org/10.1387/ijdb.113432mi

Proteomics analysis of regenerating amphibian limbs: changes during the onset of regeneration

Michael W. King, Anton W. Neff and Anthony L. Mescher

Int. J. Dev. Biol. (2009) 53: 955-969

http://dx.doi.org/10.1387/ijdb.082719mk

Vertebrate limb regeneration and the origin of limb stem cells

Susan V Bryant, Tetsuya Endo and David M Gardiner

Int. J. Dev. Biol. (2002) 46: 887-896

The cellular basis of limb regeneration in urodeles

A L Mescher

Int. J. Dev. Biol. (1996) 40: 785-795

http://www.ijdb.ehu.es/web/paper/8877452

5 yr ISI Impact Factor $(2013)=2.879$
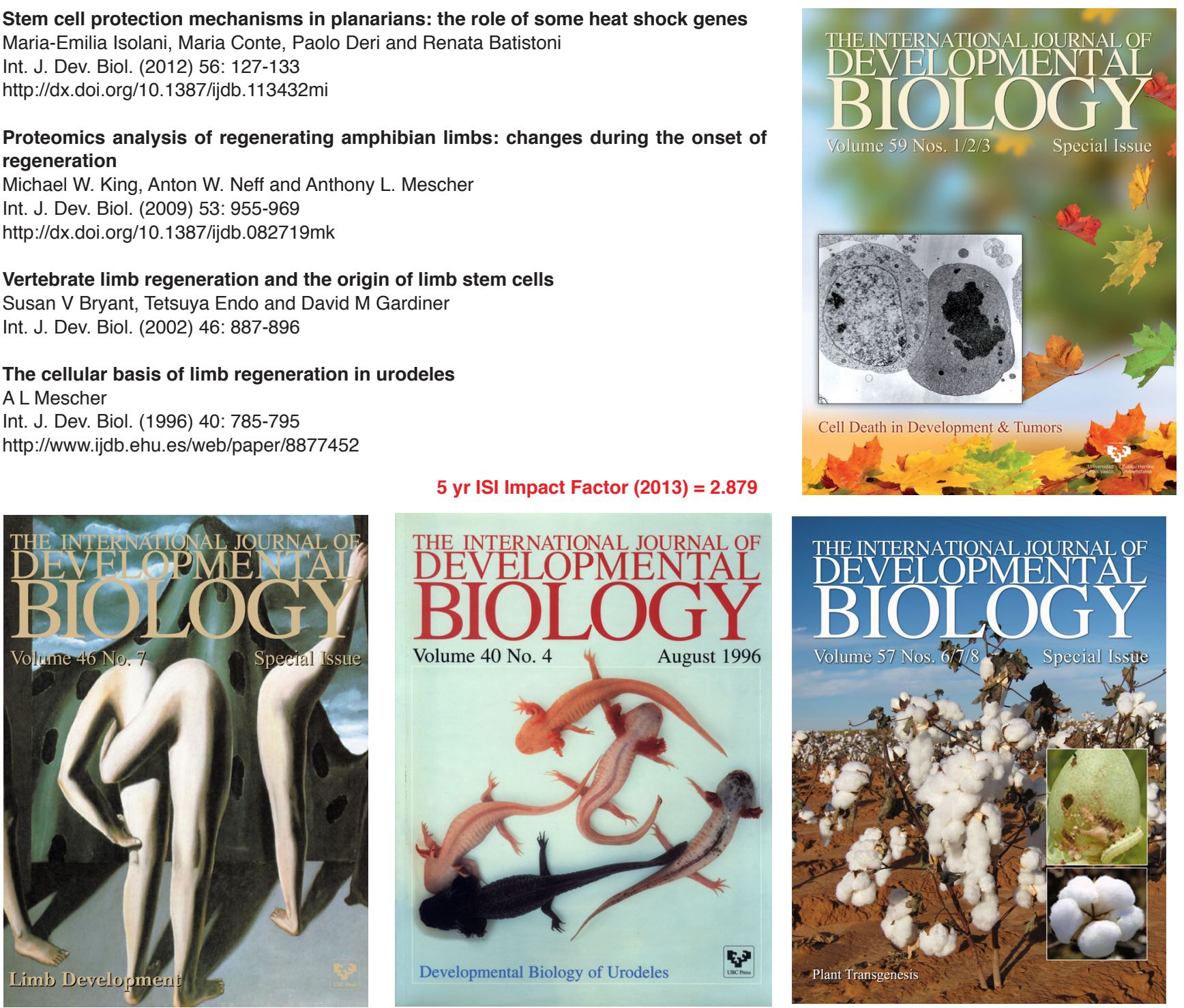